\title{
Correction to: 28 Days Later: Twitter Hashtags as "Just in Time" Teacher Professional Development
}

\author{
Spencer P. Greenhalgh ${ }^{1}$. Matthew J. Koehler ${ }^{2}$ \\ Published online: 15 June 2019 \\ (C) Association for Educational Communications \& Technology 2019
}

\section{Correction to: TechTrends (2017) 61:273-281 https://doi.org/10.1007/s11528-016-0142-4}

Since this paper's publication, it has come to our attention that two of the tables included in the paper were calculated using a slightly different dataset than the rest of our analysis. Consequently, we have recalculated the values for those tables and reviewed our manuscript for other errors. The resulting changes are minor and do not affect the overall findings or conclusions of the paper; nonetheless, we provide the following corrections by way of reference:

On p. 273, the reference to "3598 users" in the abstract should read "3583 users."

On p. 275 , the term "in vivo" does not accurately describe the coding methods used in this paper and should be disregarded.

On p. 276 , the reference to " 3598 users" in the first paragraph of the RQ1 subsection should read "3583 users."

On p. 276 , the phrase "less than $11 \%$ of participants actually posted original tweets" in the second paragraph of the RQ1 subsection should read "only approximately $11 \%$ of participants actually posted original tweets."

The online version of the original article can be found at https://oi.org/ $10.1007 / \mathrm{s} 11528-016-0142-4$

Spencer P. Greenhalgh

greenha6@msu.edu

Matthew J. Koehler

mkoehler@msu.edu

1 Department of Counseling, Educational Psychology and Special Education, Michigan State University, 447 Erickson Hall, 620 Farm Lane, East Lansing, MI 48824, USA

2 Department of Counseling, Educational Psychology and Special Education, Michigan State University, 509E Erickson Hall, 620 Farm Lane, East Lansing, MI 48824, USA
Table 2 should appear as follows:

Table 2 Participation levels in the \#educattentats affinity space

\begin{tabular}{ll}
\hline Type of participation & Percentage of users engaging \\
\hline Posting to Twitter & $77.17 \%(2765)$ \\
Composing original posts & $11.08 \%(397)$ \\
Retweeting original posts & $70.47 \%(2525)$ \\
"Liking" posts & $39.63 \%(1420)$ \\
\hline
\end{tabular}

$N=3583$

Table 3 should appear as follows:

Table 3 Concentration levels of activity in the \# educattentats affinity space

\begin{tabular}{lllll}
\hline Percentage of users & Original tweets & Retweets & Likes & Total activity \\
\hline $1 \%$ & $52.49 \%$ & $13.27 \%$ & $15.90 \%$ & $15.57 \%$ \\
$2 \%$ & $65.21 \%$ & $19.76 \%$ & $23.58 \%$ & $21.38 \%$ \\
$2.5 \%$ & $69.33 \%$ & $22.18 \%$ & $26.78 \%$ & $23.75 \%$ \\
$5 \%$ & $81.27 \%$ & $31.28 \%$ & $38.19 \%$ & $32.32 \%$ \\
$10 \%$ & $96.65 \%$ & $43.01 \%$ & $52.84 \%$ & $43.36 \%$ \\
\hline
\end{tabular}

Publisher's Note Springer Nature remains neutral with regard to jurisdictional claims in published maps and institutional affiliations. 